\title{
Geoffrey Howard Barham BlaCK
}

Geoffrey Howard Barham Black, who died in Adelaide on January 13, 1956, was born on Septemiber 14, 1893, at Burnside, South Australia. He obtained his early education at Mrs. Hübbe's private school at Knightsbridge, and in 1905 entered Saint Peter's College from which school he won a university bursary in 1911; he commenced his medical course at the University of Adelaide in 1912, graduated M.B., B.S. in 1916, and served in the A.A.M.C. in the first world war. He came to England in 1930 and worked at the Royal London Ophthalmic Hospital and at Saint Bartholomew's Hospital; having obtained the D.O.M.S. in 1931, he returned to Adelaide in 1932, and gained the F.R.A.C.S. (Oph.) in 1934. He became honorary consultant in ophthalmology at the Royal Adelaide Hospital and the Adelaide Children's Hospital.

From 1942-45 he again served in the A.A.M.C., this time as a Lt.-Col. In 1943 he was joint author with C. S. Swan and others of a paper demonstrating that rubella in the first or second month of pregnancy always results in an abnormal infant, a contribution to the work on congenital defects inaugurated by Sir Norman McAlister Gregg in 1941.

\section{ARNOLD HeRman KNAPP, 1869-1956}

By the death of Arnold Knapp at the age of 88, ophthalmology has lost one of its great figures, one that was known, respected and admired for over 50 years. His father-a pupil of von Graefe, Donders, Helmholtz, Bowman, and Critchett-emigrated from Europe to America in 1867 and more than any other may be said to have been the essential architect of American ophthalmology as we know it today. Born in New York in the year when his father began publication of the Archives of Ophthalmology, trained by his father in the hospital which he had founded-the New York Ophthalmic and Aural Institute-, and endowed with his father's wisdom and enthusiasm as well as his intellectual integrity and honesty, Arnold Knapp carried on a family tradition which has represented the best in American ophthalmology for almost a century. He rebuilt the hospital as the Herman Knapp Memorial Eye Hospital and it is now merged with the Institute of Ophthalmology of the Presbyterian Hospital, New York, and he also established the Knapp Memorial Foundation under the auspices of Columbia University for the advancement of teaching and research in ophthalmology. He took over the editorship of the Archives of Ophthalmology in 1911, and in the course of the next 38 years, made it one of the leading ophthalmic journals of the world. He was Professor of Ophthalmology at Columbia University for a quarter of a century (1903-28). His private practice was large and as a surgeon he was probably most noted for his early advocation of the intracapsular method of cataract extraction. A holder of the Howe Medal in America, he was Bowman lecturer in 1943, and was an honorary member of the Ophthalmological Societies of the United Kingdom, France, and Germany.

His interests were not confined to ophthalmology. A classical scholar of no mean merit, a connoisseur of art, a wide traveller with an intimate knowledge of Europe, he had friends and interests all over the world and loved to maintain'contact with his colleagues in many countries. Although he was best known to a generation that is now passing, his work will be remembered and his memory treasured for many years to come. 